\title{
COMBINED THERAPY IN POST-OPERATIVE GAS GANGRENE
}

\author{
J. Bittner, C. Racoviță, S. Crivda and Judith Ardeleanu \\ The Cantacuzino Institute, and The Urology Clinic, Panduri Hospital, \\ Bucharest, Roumania
}

Soon after the discovery of Clostridium welchii (Cl. perfringens), Welch (1900) recognised the association of the organism with gas gangrene developing as a complication of surgery of the urinary and alimentary tracts. Although gas gangrene was thereafter increasingly encountered as a complication of gastrointestinal surgery, observations of similar complications associated with surgery of the urinary system are extremely rare.

The concept of " spontaneous gas gangrene", introduced especially in America, arose in connexion with post-operative infections in abdominal surgery. Aldrete and Judd (1965) noted that the development of gas gangrene after an apparently uncontaminated elective abdominal operation comes as a shock to the unprepared surgeon. The term " spontaneous" applied to this form of gas gangrene implies that the source of the infection is endogenous and the surgeon is apparently absolved from the responsibility that attends exogenous infection. However, the term "spontaneous" is misleading as it denotes the absence of an obvious cause, although endogenous infection is clearly possible. For example, Canipe and Hudspeth (1964) reported a case of gas gangrene undoubtedly involving endogenous infection in a patient who sustained a minor abdominal injury without an external wound, and Clarke (1953) described three cases after closed fractures.

The present paper reports a case of gas gangrene arising as a complication of surgery of the urinary tract. This is unusual and, in addition, the successful application of a combined therapeutic regimen is instructive.

\section{CliniCAL HISTORY}

A 30-yr-old bulldozer operator was admitted to the clinic in September 1966 with a history of repeated attacks of gross haematuria and left renal colic. There was a calculus in the left inferior renal calyx. Culture of the urine yielded no growth. Dilatation of the left renal pelvis was demonstrated radiographically and a nephrolithotomy was performed. The patient left hospital 7 days after the operation in good health.

Five months later he was readmitted after recurrent attacks of severe bilateral loin pain. Urography revealed a left hydronephrosis. A temporary nephrostomy was performed for decompression. Three days after the operation, culture of the urine revealed more than $10^{5}$ organisms (Escherichia coli) per $\mathrm{ml}$, and the infection was successfully treated with chloramphenicol and tetracycline. The patient was discharged 12 days after the operation.

On 1 Jan. 1968, he was admitted again with right renal pain, fever and dysuria. His urine contained pus cells and yielded $E$. coli on culture. Intravenous pyelography subsequently revealed marked dilatation of the right renal pelvis and irregular opacification of the left pelvi-calyceal system with clubbing of some of the calyces. At operation, the right ureter was explored; ureterotomy was performed in its superior third and the pelviureteric junction and the renal cavities were explored. No calculus was found, but a

Received 23 Sept. 1969; accepted 21 Oct. 1969.

J. MED. MICROBIOL.-VOL. 3 (1970)

325 
moderate perinephritis was evident at the superior pole. The ureterotomy incision was sutured and a retroperitoneal drainage tube was inserted. The immediately post-operative period was uneventful, but after $48 \mathrm{hr}$ the patient's condition deteriorated alarmingly; he had intense thirst, nausea and vomiting, rapid breathing (32 per min.), fever and tachycardia (pulse 124 per min.). Subcutaneous crepitation was demonstrable in the tissues extending from around the wound up to the axilla.

\section{TREATMENT}

All the tissue planes of the wound were immediately opened and necrosis was evident. Several incisions were made in the zones of maximal crepitation and these and the primary wound were drained by tubes through which a solution containing 800,000 IU penicillin per $\mathrm{ml}$ was introduced. The solution also contained 0.5 per cent. sodium hypochlorite (Dakin's fluid). Aerobic and anaerobic culture of the wound exudate yielded a mixed growth of Gram-negative bacteria and Gram-positive bacilli, morphologically resembling $\mathrm{Cl}$. welchii. Accordingly, $72 \mathrm{hr}$ after the operation, parenteral treatment with broad-spectrum antibiotics (pyrrolidinomethyl tetracycline and spiramycin) and penicillin (up to $20,000,000$ IU daily) was instituted. After desensitisation of the patient, $75 \mathrm{hr}$ after the operation, polyvalent clostridial antitoxin was given intravenously ( $20 \mathrm{ml}$ polyvalent serum containing a total of 10,000 units of $\mathrm{Cl}$. welchii antitoxin). The wound was irrigated with hydrogen peroxide $\left(\mathrm{H}_{2} \mathrm{O}_{2}\right)$ several times daily and constantly covered with compresses impregnated with penicillin solution containing 1000 IU penicillin per $\mathrm{ml}$.

The patient was rehydrated with $3500 \mathrm{ml}$ intravenous 10 per cent. dextrose in saline. After a further $8 \mathrm{hr}$, the diagnosis of a clostridial infection was confirmed in the Cantacuzino Institute, where the causative organism was provisionally identified as $\mathrm{Cl}$. welchii. The combined therapy was maintained, but the polyvalent serum was replaced by a concentrated and purified monovalent $\mathrm{Cl}$. welchii antitoxin (30,000 units given in a single dose by continuous intravenous drip).

\section{Clinical COURSE}

At this stage the patient was very ill and shocked, with tachycardia, rapid shallow breathing and a blood urea concentration of $200 \mathrm{mg}$ per $100 \mathrm{ml}$; his urinary output was falling, and he had ileus and vomiting. His haemoglobin concentration fell to 42 per cent. with a red cell count of $2,340,000$ per $\mu l$ and a white cell count of 23,700 per $\mu \mathrm{l}$; his total serum bilirubin rose to $1.39 \mathrm{mg}$ per $100 \mathrm{ml}$. The marked anaemia is attributable to the haemolytic effect of the clostridial toxin.

Within $12 \mathrm{hr}$ his condition improved dramatically. His pulse rate and respiration rate decreased, his bowel sounds returned, his blood urea and electrolyte concentrations returned to normal levels and the area of crepitation diminished progressively.

The patient completely recovered from his episode of gas gangrene within 8 days, but his discharge from hospital was postponed for 35 days because he still had bouts of fever associated with his persistent urinary tract infection. 


\section{BACTERIOLOGICAL FINDINGS}

A smear of the first culture obtained from the wound exudate showed short and longer forms of stout Gram-positive bacilli with rounded ends, Grampositive cocci in pairs and Gram-negative bacilli. The mixed culture was subcultured for $5 \mathrm{hr}$ in Pittman's modified universal medium containing a selective antibiotic mixture for the inhibition of non-clostridial flora (see Bittner, Stavri, Ardeleanu and Dolofan, 1967; Bittner, Voinesco and Ardeleanu, 1967). Thereafter, further subcultures were made in deep Weinberg tubes, and on the surface of Willis-Hobbs half-antitoxin plates (Willis and Hobbs, 1959) spread with Cl. welchii antitoxin; these were incubated anaerobically at $37^{\circ} \mathrm{C}$. At the same time, a litmus milk medium was seeded and the development of the stormy clot reaction characteristic of $C l$. welchii within $8 \mathrm{hr}$ after the operation allowed us to give a provisional diagnosis during the same day although the organism was not yet isolated in pure culture.

The other cultures yielded a strain of $\mathrm{Cl}$. welchii type A, that produced potent phospholipase (lecithinase, alpha toxin) when grown in modified Pope's medium with dextrin and starch (Stavri, Bittner and Fîciu, 1964).

Blood culture performed during the invasive phase of the infection yielded only Proteus mirabilis.

\section{Discussion}

This case presented all of the classical local and general clinical features of gas gangrene. The bacteriological identification of Clostridium welchii was established on the second day of the acute disease, but combined therapy was initiated as soon as gas gangrene was suspected. This involved prompt surgery of the affected tissues and the administration of local antibacterial and parenteral antibiotic agents with polyvalent antitoxin followed by monovalent antitoxin. The treatment controlled the infection and there was a spectacular resolution of the disease.

Baker (1964) considered that "In view of the ubiquity of potentially pathogenic clostridia and the frequency of wound contamination with these organisms, serious [clostridial] infections are surprisingly infrequent".

The infection in the present case may have been exogenous; Lowbury and Lilly (1955) demonstrated the wide occurrence of $\mathrm{Cl}$. welchii and its presence in the air of operating theatres. However, these authors grew relatively few colonies of $\mathrm{Cl}$. welchii from a $1-\mathrm{m}^{3}$ sample of air. On the other hand, human and animal intestines regularly contain Cl. welchii and other anaerobes (Collee, Knowlden and Hobbs, 1961; Săsărman and Horodniceanu, 1961; Bittner, Voinesco and Ardeleanu, 1967); and the proportion of $\mathrm{Cl}$. welchii may be quite large (Drasar, 1967; Horodniceanu, 1970). Thus, there are good reasons for assuming that post-operative gas gangrene may be more often endogenously acquired when gastro-intestinal surgery is involved. Extension of Cl. welchii from the gut into neighbouring tissues may be facilitated or directly mediated by the surgeon (see Ahmed, 1965). Whyland and Levin (1960) have also drawn attention to the possibility of clostridial embolism. 
Eliason, Erb and Gilbert (1937) were able to find $\mathrm{Cl}$. welchii in the normal peritoneal cavity. If this finding is accepted, it greatly enlarges the scope of the abdominal surgeon's problem. It is clear that minimal intestinal lesions such as those associated with a simple colitis may allow $\mathrm{Cl}$. welchii and other anaerobes to enter the bloodstream and spread by haematogenous routes. Weinberg, Nativelle and Prévot (1937) quoted numerous authors who were able to demonstrate the asymptomatic presence of $\mathrm{Cl}$. welchii in nearly all human tissues. The possibility of haematogenous dissemination of $\mathrm{Cl}$. welchii and of more exacting anaerobes was undoubtedly confirmed by Pitzler, Markgraf and Oehring (1967), who described a patient who developed gas gangrene of the right hand after injuring it with a hammer; there was no evidence of an external wound, but $\mathrm{Cl}$. novyi ( $\mathrm{Cl}$. oedematiens) and $\mathrm{Cl}$. aerofoetidum were isolated from the affected tissue. During the course of the disease the patient became agitated and it was necessary to bind him to the bed. The authors assumed that this was the cause of ischaemia which, after $2 \mathrm{wk}$, led to the appearance of gas gangrene in the left hand, from which the same species of clostridia were isolated. Bak (1967) emphasised the importance of ischaemia as a precipitating factor in gas gangrene.

Aldrete and Judd (1965) concluded that, as the anaerobes are regularly present and the necessary conditions may be provided by surgical intervention, auto-infection seems to be the most likely mechanism of post-operative anaerobic sepsis. This also holds for the " spontaneous" complication of gas gangrene following surgery of the urinary system. In our laboratory, we have demonstrated the asymptomatic occurrence of clostridia in urine (Bittner et al., 1969), but the incidence of these organisms is very low ( 1 positive culture in 400-500 samples). Our results are similar to those of Headington and Beyerlein (1966) who examined large numbers of cultures.

The low incidence of clostridia in urine may explain the rarity of gas gangrene associated with surgery of the urinary tract. Apart from the account of Welch (1900), we were able to find very few reports of such cases. One case, described by Gasanov (1967), was a 3-yr-old boy who developed gas gangrene of the scrotum caused by $\mathrm{Cl}$. welchii and associated with a urethral calculus. This case should not be confused with those reported by Himal and Duff (1967), in which gas gangrene of the scrotum developed as a complication of neglected peri-anal suppuration. In the present case, the initiation of anaerobic infection was favoured by the sequelae of a chronic infection and by an episode of pyogenic infection.

The clinical diagnosis of gas gangrene is obvious when the disease is at an advanced stage, but diagnosis is more difficult in the initial period, and prompt diagnosis greatly influences the patient's chance of survival. Much attention has been given to the importance of crepitation in the tissues around the wound as a diagnostic sign, but this teaching has been criticised recently because (i) crepitus is a relatively late development, (ii) gas gangrene may develop in the absence of crepitus, and (iii) some aerobic organisms may give rise to infections associated with crepitus. Hunnicutt, commenting on Aldrete and Judd's communication (p. 754), considered that crepitation can be detected earlier if a 
stethoscope is used. In our case, crepitus was an early sign and entirely determined the rapidity of the diagnosis.

At present, it is not possible to ensure an immediate bacteriological diagnosis of the causative organism in gas gangrene. The immunofluorescent staining procedure of Batty and Walker (1965) allows prompt identification of $\mathrm{Cl}$. septicum and $\mathrm{Cl}$. oedematiens $(\mathrm{Cl}$. novyi), but $\mathrm{Cl}$. welchii cannot be reliably identified in this way. Moreover, it is not always possible to obtain direct smears of adequate quality. In the absence of an immediate and reliable bacteriological diagnosis, simple examination of Gram-stained direct smears of the wound exudate may nevertheless provide important clues. We confirm the opinion of McSwain, Sawyers and Lawler (1966) that, when such a smear is examined, the appearance of clostridia is sufficiently characteristic for the genus and justifies the initiation of antitoxic therapy with polyvalent serum. Certainly, when the precise bacteriological diagnosis is subsequently established and a single species is involved, as in our case, the administration of a monovalent antitoxin is indicated.

Some authors consider that surgical treatment is of paramount importance and that any other procedures are merely ancillary (see Aldrete and Judd). Some question the value of antitoxin (Kiranow, 1966), whereas others support its use (Spann and Clingan, 1968). The value of antibiotic therapy is undisputed and the antibiotic of choice is penicillin, given in massive doses. We strongly recommend the additional local use of penicillin in solution and we consider that hydrogen peroxide solution should also be applied locally. A series of other antibiotics may have a place in special cases.

Enthusiastic claims have been made for the efficacy of hyperbaric oxygen in the treatment of gas gangrene and the Dutch workers imply that this can replace all other therapeutic measures, including surgical intervention (see Brummelkamp, Hogendijk and Boerema, 1961). However, the experience of others has been more varied (Smith et al., 1962). The use of hyperbaric oxygen involves toxic hazards that should be borne in mind. Clinicians who have to deal with gas gangrene are meanwhile anxious to have the conflicting reports on hyperbaric oxygen therapy resolved.

Spann and Clingan consider that the efficient treatment of gas gangrene necessitates early diagnosis, wound excision, administration of antibiotics, local oxygen and antitoxins, sustaining measures and hyperbaric oxygen. It should be noted that these authors did not apply all of the listed remedies to the patients cured by them.

In a series of animal experiments performed by us, the success of combined therapy in gas gangrene could be demonstrated without any surgical intervention. Antitoxin and ethylenediaminotetraacetic acid (EDTA-sodium complex) were given parenterally, and penicillin was given locally (Bittner, 1963; Bittner and Ardeleanu, $1965 a$ and $b$; Bonciu et al., 1966). Naturally the muscle mass in which the gas gangrene infection develops in a laboratory animal is much smaller than that involved in man, but nevertheless some conclusions useful for human treatment may be drawn from these experiments. We attach importance to the local administration of antibiotics, considering that the impaired 
vascularity associated with an anaerobic wound is likely to interfere with the access of parenterally administered antibiotic.

The spectacular improvement in the condition of the patient described in the present paper within $12 \mathrm{hr}$ of starting treatment with antitoxic serum and antibiotics suggests that the neutralising effect of specific antitoxin was a major factor, but the value of local combined therapy which included surgical management and instillation of hydrogen peroxide and penicillin merits consideration.

Our experience in this field leads us to recommend the following treatment schedule for gas gangrene: (a) polyvalent gas gangrene antitoxic serum 50,000200,000 units, or monovalent antitoxin as indicated by the bacteriological evidence, should be given intravenously over a period of $24-48 \mathrm{hr}$; preliminary desensitisation may be necessary; $(b)$ thorough surgical attention to the wound is of paramount importance; (c) wound irrigation with hydrogen peroxide solution should be performed several times daily and the wound should be regularly flushed with saline containing $1000 \mathrm{IU}$ penicillin per $\mathrm{ml}$; $(d)$ crystalline penicillin 5-20 M.units should be given daily by intramuscular injection; (e) where possible, exposure of the wound to a flow of oxygen may be beneficial.

Post-operative gas gangrene is often an unpredictable complication and prophylaxis is difficult to ensure. Sawyer, quoted by Aldrete and Judd, considered that diabetic patients account for as much as three-quarters of all cases developing post-operative gas gangrene. Others deny that there is such an increased incidence of this post-operative complication in diabetics. We cannot agree with those surgeons who propose to perform all operations under the cover of a prophylactic antibiotic, but surgery of the hip or thigh of an elderly patient calls for very thorough preparation of the skin and parenteral penicillin as prophylactic measures (Br. Med. J., 1969; Parker, 1969). Welborn (1964) considered that surgeons may reasonably pay more attention to preservation of the blood supply and avoidance of devitalisation of the rectus muscle in upper abdominal operations. This principle could be applied to operations involving other muscle masses, as ischaemia is the principal contributory factor in the development of spontaneous gas gangrene.

\section{SUMMARY}

A case of gas gangrene arising as a complication of exploratory ureterotomy in a patient with chronic bilateral renal infection is described. The bacteriological diagnosis was established on the second day after onset; a toxigenic strain of Clostridium welchii type A was isolated from the wound. Proteus mirabilis was isolated from the wound and from the patient's bloodstream.

Combined therapy included prompt surgical treatment and repeated local instillations of $\mathrm{H}_{2} \mathrm{O}_{2}$ and a saline solution containing $1000 \mathrm{IU}$ penicillin per $\mathrm{ml}$. Parenteral antibiotic therapy included 20 M.units of penicillin daily, and pyrrolidinomethyl tetracycline and spiramycin. A dose of 10,000 units of $\mathrm{Cl}$. welchii antitoxin was given intravenously in a polyvalent clostridial antitoxic serum, followed by 30,000 units as monovalent serum when the diagnosis was confirmed. 
The patient's condition improved dramatically within a few hours of the start of the combined therapy and recovery was complete within 8 days.

The pathogenesis, diagnosis and current methods of treatment of gas gangrene are discussed, with special reference to post-operative gas gangrene.

The authors are greatly indebted to Dr J. G. Collee, Edinburgh University Medical School, for invaluable help in the preparation of the manuscript.

\section{REFERENCES}

Ahmed, N. . . . . . . . . . . . . . 1965. Br. J. Surg., 52, 276.

Aldrete, J. S., ANd Judd, E. S. . . . 1965. Archs Surg., Chicago, 90, 745.

BAK, S. . . . . . . . . . . 1967. Zentbl. Chirurg., 92, 2261.

Baker, E. E. . . . . . . . . . . . 1964. Amer. J. Surg., 107, 689.

Batty, Irene, and Walker, P. D. . . 1965. J. Appl. Bact., 28, 112.

Bittner, J. . . . . . . . . . 1963. Archs roum. Path. exp. Microbiol., 22,

Bittner, J., ANd Ardeleanu, Judith . 1965a. Ibid., 24, 167.

BITTNER, J "̈ "̈ "

JUdith, MAȘE, SUZANA, TOMAS,

Emilia, Rădulescu, Alexandra, and

SOREA, ECATERINA

Bittner, J., Stavri, D., Ardeleanu, 1967. Ibid., 26, 57. JUDITH, AND DOLOFAN, L.

BitTNer, J., VOINESCO, VIORICA, AND 1967. Ibid., 26, 853. ARDELEANU, JUdith

Bonciu, C., Bittner, J., Petrovici, 1966. Ibid., 25, 665. Monica, and Ardeleanu, Judith

BRITISH MEDiCAL JoURNAL (Leading 1969. Br. Med.J., 3, 665. ARTICLE)

Brummelkamp, W. H., Hogendijk, J., 1961. Surgery, St Louis, 49, 299. AND BOEREMA, I.

CAnipe, T. L., and Hudspeth, A. S.

ClaRKe, P. R. R. . . · · · ·

1964. Archs Surg., Chicago, 89, 544.

1953. Lancet, 2, 1207.

COllee, J. G., KNowlden, Jill A., AND HobBs, BetTy C.

Drasar, B. S. . . . . . . . . 1967. J. Path. Bact., 94, 417.

Eliason, E. L., Erb, W. H., ANd Gilbert, 1937. Surg. Gynec. Obstet., 64, 1005. P. D.

GASANOV, R. K.

1967. Urol. Nefrol., 32, 60.

Headington, J. T., and Beyerlein, 1966. J. Clin. Path., 19, 573. BARBARA

Himal, H. S., AND DufF, J. H.

1967. Canad. Med. Assoc. J., 97, 1541.

Horodniceanu, THEA

1970. Archs roum. Path. exp. Microbiol., 29, in press.

Kiranow, I. G.

1966. Zentbl. Chirurg., 91, 904.

LowbURy, E. J. L., AND Lilly, H. A.

1955. J. Path. Bact., 70, 105.

McSwain, B., Sawyers, J. L., and 1966. Ann. Surg., 163, 859. LAWLER, M. R., JR

PARKer, M. T. . . . . . . . . 1969. Br. Med. J., 3, 671.

Pitzler, K., Markgraf, E., AND 1967. Mschr. Unfallheilk. Versich-Med., 70, OEHRING, $\mathbf{H}$.

Săsărman, A., and Horodniceanu, 1961. Archs roum. Path. exp. Microbiol., 20, THEA 471. 
Smith, G., Sillar, W., Norman, J. N., 1962. Lancet, 2, 756.

Ledingham, I. MCA., Bates, E. H., AND SCOTT, A. C.

Spann, J. L., ANd Clingan, F. A. . . 1968. J. Okla. St. Med. Assoc., 61, 3.

Stavri, D., Bittner, J., AND Fîciu, S. . 1964. Archs roum. Path. exp. Microbiol., 23, 1025.

Weinberg, M., Nativelle, R., AND 1937. Les microbes anaérobies, Paris, p. 192. PrÉvot, A. R.

Welborn, M. B. . . . . . . . 1964. Amer. Surgeon, 30, 295.

WELCH, W. H. . . . . . . . . 1900. Bull. Johns Hopkins Hosp., 11, 185.

Whyland, W. A., ANd Levin, M. N. . 1960. Amer. J. Surg., 99, 77.

Willis, A. T., AND HobBs, G. . . . 1959. J. Path. Bact., 77, 511. 